\title{
Enzymatic Degradation and Pilot-Scale Composting of Cellulose-Based Films with Different Chemical Structures
}

\author{
Ilona Leppänen ${ }^{1} \cdot$ Minna Vikman $^{1} \cdot$ Ali Harlin $^{1} \cdot$ Hannes Orelma ${ }^{1}$ (1)
}

Published online: 27 November 2019

(c) The Author(s) 2019

\begin{abstract}
In this study, we investigated the enzymatical degradability and pilot-scale composting of 14 cellulose-based materials. The materials analyzed here were cellulose regenerated from ionic liquid (EMIM[OAc]), carboxymethyl cellulose (CMC) crosslinked by aluminum salt (Al-salt), methyl cellulose, cellulose acetate, butylated hemicellulose: DS: 1, DS: 0.4, and DS: 0.2 , cellophane, wet strength paper, nanocellulose, paper partially dissolved by IL, cellulose carbamate, cellulose palmitate, and cellulose octanoate. The aim of the study was to show how chemical substituting and the substituent itself influence the biodegradability of cellulose materials. The enzymatic degradation and pilot-scale composting of these films shows the correlation between the hydrolysis rate and degree of substitution. The enzymatic hydrolysis of cellulose-based films decreased exponentially as the degree of substitution increased. Modifying cellulose to the extent that it gains the strength needed to obtain good mechanical properties, while retaining its natural biodegradability is an important factor when preparing alternatives for plastic films.
\end{abstract}

\section{Graphic Abstract}
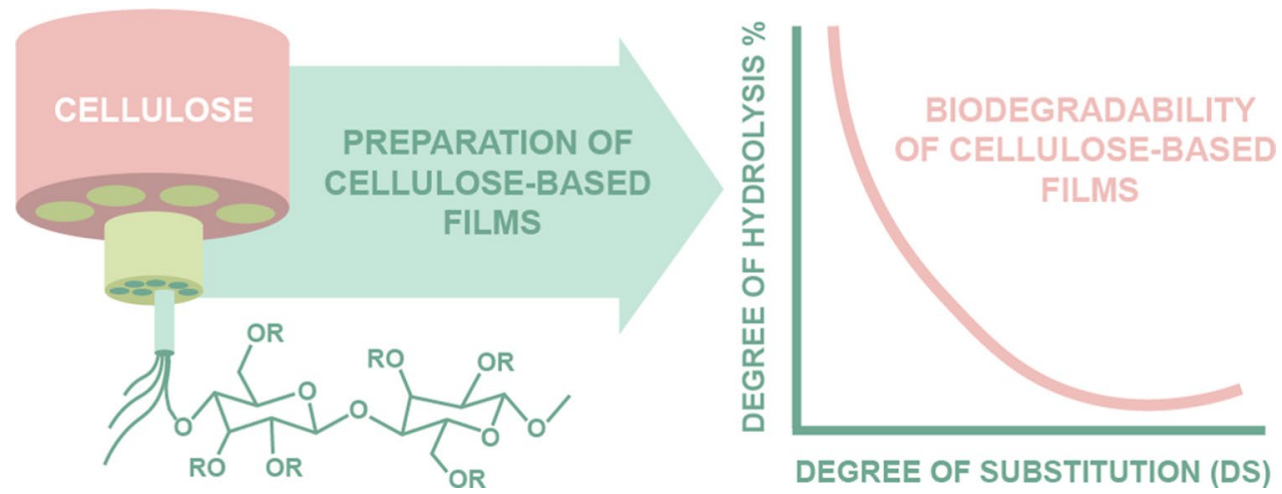

Keywords Cellulose films $\cdot$ Biodegradability $\cdot$ Composting $\cdot$ Degree of substitution

Electronic supplementary material The online version of this article (https://doi.org/10.1007/s10924-019-01621-w) contains supplementary material, which is available to authorized users.

Hannes Orelma

hannes.orelma@vtt.fi

1 VTT - Technical Research Centre of Finland Ltd, Tietotie 4E, 02044 Espoo, Finland

\section{Introduction}

Packaging materials are crucial for our current business ecosystems ensuring the global transport of everyday goods and food. Fossil based plastics cover a large part of the used packaging materials worldwide and plastic production has exploded in the past decades. Currently, the global production of plastics is almost 350 million tons per year, and from that packaging covers almost $40 \%$ [1]. Packaging materials 
are often used only once and subsequently incinerated or recycled. In Europe, $40.8 \%$ of the collected plastic packaging waste is recycled, $20.4 \%$ ends up in a landfill and 38.8\% is used for energy recovery [1]. However, the recycling systems in many countries are not as efficient and a large part is accumulated in the oceans and environment causing serious ecological problems, such as micro- and nanoplastics [2]. It is estimated, that 8.8 million tons of plastic waste ends up in oceans every year [3]. Consequently, the packaging industry has been guided towards more sustainable, biodegradable and renewable materials. One already utilized solution is the use of plant-based cellulose $\left(\mathrm{C}_{6} \mathrm{H}_{10} \mathrm{O}_{5}\right)_{\mathrm{n}}$ that is the most abundant biopolymer found in nature with outstanding properties, such as polyfunctionality, high chain stiffness, biodegradability and broad chemical modifying capacity $[4$, 5]. From cellulose containing materials, wood is the most important cellulose source that is already widely used in the paper and board based packaging products [6]. Furthermore, it also has applications in packaging in the form of regenerated cellulose, which is used to manufacture transparent packaging films [7].

Cellulose is a linear polymer consisting of $\beta(1 \rightarrow 4)$ linked D-glucopyranose units. It is one of the primary components of the wood cell wall together with hemicellulose and lignin [4]. The wood cell wall contains three subunits, wood fibers, cellulose nanofibrils and polymeric cellulose that can all be industrially separated for packaging applications [8]. Polymeric cellulose is called regenerated cellulose when used in applications, such as cellophane film. Cellulose, hemicellulose and lignin are naturally biodegraded in nature by various microorganisms. In soil, filamentous fungi are most potent in degrading cellulose biomass [9]. Various different enzymes, called cellulases, are known to take part in the biodegradation of cellulose. These can be categorized into endoglucanases, cellobiohydrolases and cellobiases, which act in synergy to degrade cellulose into glucose [10]. Enzymes called hemicellulases and ligninolytic enzymes take part in the biodegradation of hemicellulose and lignin, respectively [11]. The fact that cellulose is simultaneously naturally biodegradable and has good film forming properties has raised interest in the use of cellulose in packaging industry.

Due to the high molecular weight, crystallinity and hydrophobic interactions in the cellulose backbone, cellulose is insoluble in water and most organic solvents $[4,12]$. The cellulose structure can be chemically modified, making it e.g. thermoplastic and soluble in various solvents [5]. The hydroxyl groups $(-\mathrm{OH})$ on the cellulose backbone can be substituted with different substituents producing a variety of different cellulose derivatives. The degree of substitution (DS) is the average number of substituted hydroxyl groups per a glucose unit (the maximum being 3 , due to 3 available $-\mathrm{OH}$ groups). Chemical modifications include for example esterification and etherification and they can alter the biodegradability of cellulose $[13,14]$. One of the most extensively studied cellulose derivatives is cellulose acetate (CA) [14-18]. In these studies, it has been shown that an increase in the DS leads to lower biodegradability. It has also been shown that prior to the degradation of the cellulose backbone, the acetate groups have to be removed via deacetylation by acetyl esterases [19]. Therefore, if the DS is high enough, cellulases are unable to hydrolyze the cellulose backbone. In addition, if the DS is close to the maximum also esterases are unable to attach to the cellulose surface and cleave the acetate bonds [18, 20]. Biodegradation of methyl cellulose and its nanocomposites has been studied measuring its $\mathrm{CO}_{2}$ evolution during 6 weeks. It was concluded, that the crosslinking of methyl cellulose hinders the biodegradation process [21]. Biodegradation of carboxymethyl cellulose has been studied using a fungal strain and according to the Organization for Economic Cooperation and Development (OECD) Test Guideline 301 A [22, 23]. It was concluded, that CMC (DS: 0.7) can be expected to biodegrade completely in nature. It has also been reported that derivatized thermoplastic celluloses are typically lacking biodegradability, but with wise selection of substituents the biodegradation can be enabled [13]. Even though biodegradation of some cellulose samples has been studied, there is still lack of a comprehensive study on biodegradability of a variety of cellulose-based packaging materials that can potentially replace synthetic packaging films.

Methods assessing biodegradation include visual observation e.g. weight loss, loss in physical properties, $\mathrm{CO}_{2}$ evolution and biochemical oxygen demand (BOD) [24, 25]. Several standardized methods are available for the determination of biodegradability of chemicals, plastics, and packaging materials (OECD, ISO, CEN). Biodegradability can be defined as utilization of test material by microbes leading to formation of carbon dioxide, water, mineral salts and new microbial cellular constituents in aerobic conditions if the material is completely mineralized (e.g. EN14046, Packaging - Evaluation of the ultimate aerobic biodegradability of packaging materials under controlled composting conditions - Method by analysis of released carbon dioxide) [26]. During biodegradation of polymers, they are first depolymerized to smaller components by extracellular enzymes produced by microbes. After that, they can be transported through cellular membranes to microbial cells where they are further mineralized. Biodegradability of cellulose is dependent on cellulose's degree of crystallinity, structure, functional groups, cross-linking and molecular weight [9]. It is observed that the amorphous units of cellulose are more readily hydrolyzed than the crystalline regions [27]. Cellulose has four different crystalline forms, allomorphs (cellulose I, II, II, and IV) and their polymorphs [4, 28]. 


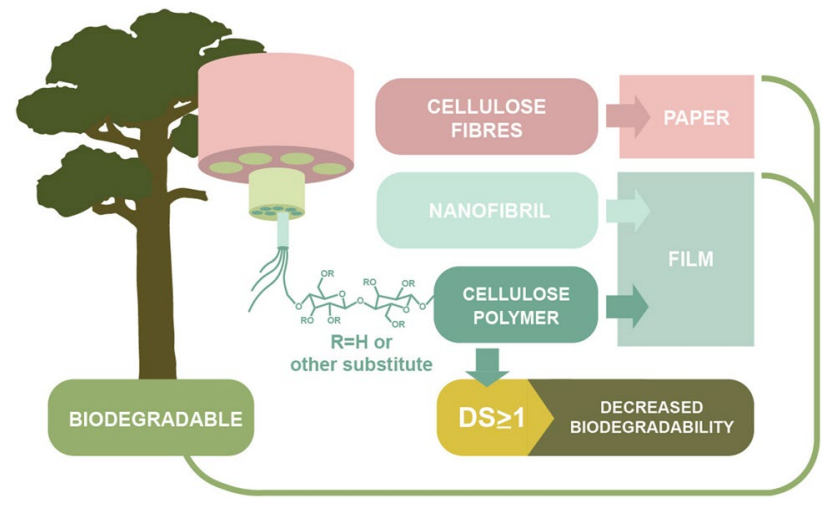

Scheme 1 Schematic image of the hierarchical structure of cellulose from wood fibers to polymeric cellulose and their potential applications as paper and films. Chemical grafting of cellulose increases the degree of substitution (DS), which leads to decreased biodegradability. The closed loop demonstrates the circularity and renewability of cellulose

In the higher plants, cellulose $I_{\beta}$ is the predominant form and cellulose $\mathrm{I}_{\alpha}$ in algae, bacterial cellulose, and starch. When cellulose is dissolved and subsequently precipitated (regenerated), the orientation of the cellulose chains and hydrogen-bonding are changed and cellulose II, also known as "man-made" cellulose, is formed. It has been shown, that enzymatic hydrolysis of cellulose II is much faster than of cellulose I, because the crystalline structure of cellulose II is much more accessible for the attack of cellulase enzymes than cellulose I [29]. The other two crystalline forms of cellulose are cellulose III and IV, of which cellulose III is achieved by chemically treating cellulose I or II and cellulose IV by treating cellulose II with heat. It has been shown that the biodegradation of cellulose III exceeds the biodegradation of cellulose I and II [30].

In this study, the biodegradability of cellulose-based films was studied by using enzymatic hydrolysis and pilot-scale composting test (Scheme 1). The studied materials were regenerated cellulose with and without different substituents, CNF, and paper. The prepared sample materials were characterized by FTIR and UV-Vis, visualized by SEM, and additionally their tensile properties were measured. Enzymatic degradation of the films was determined by enzymatic hydrolysis under laboratory conditions. Degradation of cellulose films was conducted by pilot-scale composting tests representing the industrial composting process. It was observed, that cellulose degradation is highest for pure cellulose and the chemical grafting decreases the enzymatic biodegradability despite of what the substituent is.

\section{Experimental}

\section{Materials}

1-Ethyl-3-methylimidazolium acetate (EMIM[OAc], purity $>95 \%$ ) was purchased from IoLiTec $\mathrm{GmbH}$, Germany. Cellulose acetate $(\mathrm{Mn} \sim 30,000$, degree of substitution $39.8 \mathrm{wt} \%$ acetyl), sodium carboxymethyl cellulose $\mathrm{Mw} \sim 250,000$, DS: 0.7$)$, cellulose from spruce (acid washed), methyl cellulose (viscosity $25 \mathrm{cp}$, DS 1.7) and sodium acetate were purchased from Sigma-Aldrich. Aluminium sulfate octadecahydrate (purity $>98 \%$ ) was purchased from Acros Organics, Finland. Cellophane was purchased from Innovia films. Econase and Ecopulp X-200 enzyme mixes were purchased from AB Enzymes Finland and Gamanase and Novozyme 188 from Novozymes. All other chemicals were analytical grade. All water used in the study was Milli-Q purified (referred as di $\mathrm{H}_{2} \mathrm{O}$ ).

\section{Preparation and Origin of Investigated Specimens}

Altogether fourteen different cellulose-based films were included in this study. The preparation strategy or origin of each tested material is listed in Table 1.

\section{Fourier Transform Infrared Spectroscopy (FT-IR)}

Fourier transform infrared spectroscopy measurements (FTIR) were carried out using a Thermo Scientific Nicolet iS50 FT-IR spectrometer with an ATR diamond (Thermo Scientific, USA). All spectra were obtained from 32 scans with a resolution of $4 \mathrm{~cm}^{-1}$. Throughout the wavenumber range from 400 to $4000 \mathrm{~cm}^{-1}$. Dry films were placed on the ATR crystal and the IR spectrum was measured. At least three repetitions per sample were conducted.

\section{Scanning Electron Microscopy (SEM)}

To determine the visual structure of the films, Scanning Electron Microscopy imaging was carried out with a Merlin Field Emission (FE)-SEM (Carl Zeiss NTS GmbH, Germany). Small, ca. $1 \mathrm{~cm}^{2}$, pieces were cut from the cellulosebased films and attached on SEM sample holders that were coated with carbon tape. Film samples on the holders were subsequently coated with gold by sputtering $(30 \mathrm{~mA}, 30 \mathrm{~s})$ to improve sample conductivity. All images were imaged with the electron gun voltage of $3-5 \mathrm{kV}$ and the grid current of $60 \mathrm{pA}$. The pixel resolution in the images was $2048 \times 1536$ pixels. Images were taken from approximately three different locations. 
Table 1 Tested cellulose materials

\begin{tabular}{ll}
\hline Material & Preparation process \\
\hline a Cellulose regenerated from ionic liquid (IL) & A $10 \mathrm{w} / \mathrm{w} \%$ cellulose solution was prepared dissolving cellulose from spruce in \\
& ionic liquid (EMIM[OAc]) under heat and mixing. Subsequently, a film was \\
& casted on a glass surface using an Erichsen film applicator with the thickness of \\
& $500 \mu \mathrm{m}$. The cellulose IL film on the glass was placed in water to regenerate for \\
& $1.5 \mathrm{~h}$. The film was dried between absorbent papers at RT for 3 days. Average \\
film thickness $74 \mu \mathrm{m}$
\end{tabular}

b Carboxymethyl cellulose cross-linked with aluminum

c Nanocellulose

d Methyl cellulose

$\mathrm{e}$

Cellulose acetate

f Paper partially dissolved by ionic liquid

g Cellophane

h Wet strength paper

i Cellulose carbamate

j-1 Butylated hemicelluloses
A 4 w/w\% carboxymethyl cellulose (CMC) solution was prepared by first dissolving CMC (DS 0.7) in hot water while mixing. A $1 \mathrm{~mm}$ thick CMC film was applied on a transparency film manually using comb applicator. The film was left to dry overnight at RT. The dry CMC film was immersed in $0.1 \mathrm{M}$ $\mathrm{Al}_{2}\left(\mathrm{SO}_{4}\right)_{3}$ for $3 \mathrm{~min}$ and subsequently rinsed with $\mathrm{diH}_{2} \mathrm{O}$ for $3 \mathrm{~min}$. The crosslinking with aluminum was done to increase the water resistance of the CMC film. The CMC-Al film was dried between absorbent papers. Average film thickness $32 \mu \mathrm{m}$

Nanocellulose film was manufactured at VTT with VTT's pilot scale concept in Espoo [55]. Cellulose nanofibrils, in consistency of $1.8 \mathrm{wt} \%$, with $30 \mathrm{wt} \%$ of sorbitol (plasticizer) was solvent casted on polypropylene foil (wet thickness $1-1.5 \mathrm{~mm}$ ) and allowed to dry at RT overnight. Average film thickness $28 \mu \mathrm{m}$

$8 \mathrm{w} / \mathrm{w} \%$ methyl cellulose (MC) solution was prepared by first dissolving the MC in $1 / 3$ hot $\mathrm{diH}_{2} \mathrm{O}$ and after dispersion the remaining $2 / 3 \mathrm{diH}_{2} \mathrm{O}$ was added cold. $700 \mu \mathrm{m}$ thick films were casted using the Erichsen film applicator. The films were left to dry at RT overnight. Average film thickness $30 \mu \mathrm{m}$

$20 \mathrm{w} / \mathrm{w} \%$ cellulose acetate (CA) solution was prepared in acetone. $500 \mu \mathrm{m}$ thick film was casted on a transparency film using the Erichsen film applicator. The solvent was evaporated at RT overnight. Average film thickness $65 \mu \mathrm{m}$

The paper partially dissolved by IL was prepared following a procedure shown previously [56]. The treatment solution was prepared by diluting 1-ethyl-3-methylimidazolium acetate (EMIM[OAc]) with water to $75 \mathrm{wt} \%$ concentration. Paper made from bleached pine kraft pulp was dipped into the EMIM[OAc] solution for 3 min to absorb IL-water solution into the paper structure. The partial dissolution was carried out in the oven $\left(95^{\circ}, 16 \mathrm{~h}\right)$, where first the water from IL evaporated and then the fibres partially dissolved. The films were dried between absorbent papers. Average film thickness $135 \mu \mathrm{m}$

Cellophane used in this study is commercially available (uncoated and unplasticized). Cellophane was studied as such, used without any pre-treatments. Average film thickness $28 \mu \mathrm{m}$

Wet strength paper used in this study is a commercial product obtained from UPM. The paper was studied as such without any pre-treatments. Average paper thickness $110 \mu \mathrm{m}$

A $6 \mathrm{wt} \%$ cellulose carbamate (CCA) solution was prepared from CCA powder by dissolving in two steps. First in mildly alkaline and secondly in cold and highly alkaline conditions. The films were casted on a glass surface with steel frames. The glass was immersed in a $10 \mathrm{wt} \% \mathrm{H}_{2} \mathrm{SO}_{4}$ bath until the film came of and subsequently rinsed with water. Before drying the films were immersed in a 13 $\mathrm{wt} \%$ glycerol bath for $10 \mathrm{~s}$. The films were dried in $90^{\circ}$ for $20 \mathrm{~min}$. Average film thickness $33 \mu \mathrm{m}$. DS: 0.11

Butylated hemicellulose (BHC) films were prepared with three different degrees of substitution (DS 1, 0.4 and 0.2). BHC samples were prepared following the study by Nypelö et al. [44]. Freeze-dried BHC samples were dissolved in $\mathrm{diH}_{2} \mathrm{O}$ to make $\sim 15 \mathrm{w} / \mathrm{w} \%$ solutions. The films were then casted manually on a transparency film using a $1 \mathrm{~mm}$ comb applicator. Films were dried overnight at RT. Average film thicknesses were $83 \mu \mathrm{m}$ (BHC DS: 1), $85 \mu \mathrm{m}$ (BHC DS: 0.4), $74 \mu \mathrm{m}$ (BHC DS 0.2) 
Table 1 (continued)

\begin{tabular}{ll}
\hline Material & Preparation process \\
\hline $\mathrm{m}, \mathrm{n}$ Cellulose palmitate (C16) and cellulose octanoate (C8) & $\begin{array}{l}\text { Cellulose palmitate and cellulose octanoate ester films were prepared as described } \\
\text { previously [40, 57]. The cellulose esters were synthesized from bleached kraft- }\end{array}$ \\
& wood pulp. In the synthesis, dissolved cellulose was grafted by fatty acids. More \\
& specific information regarding the C16 material is provided in the article [40]. \\
& Cellulose octanoate (C8) was synthetized by esterification with caprylic acid, \\
& and cellulose palmitate (C16) by palmitic acid. C8 and C16 indicate the length \\
& of the fatty acid chain. Average film thicknesses were $175 \mu \mathrm{m}(\mathrm{C} 16), 129 \mu \mathrm{m}$
\end{tabular}

\section{Mechanical Properties}

Tensile strength, Young's modulus and strain at break of the films were measured by a Lloyd LS5 materials testing machine (AMETEK measurement and calibration technologies, USA) at $23{ }^{\circ} \mathrm{C}$ and $50 \% \mathrm{RH}$ with a load cell of $100 \mathrm{~N}$. All samples were stabilized in the given conditions at least overnight. The initial grip distance was constant $30 \mathrm{~mm}$ and the rate of the grip separation $10 \mathrm{~mm} \mathrm{~min}^{-1}$. The samples were cut into $15 \mathrm{~mm}$ wide specimens with a lab film cutter. Seven replicates of each sample were measured. Thicknesses of each specimen was measured with a digital caliber from 3 different points. The average thickness was used for the calculations.

\section{Optical Properties}

The transparency of the cellulose-based films was measured using a Perkin Elmer Lambda 900 UV/VIS/NIR spectrometer (Perkin-Elmer, USA) with a film holder. Transmittance of all films was measured by using wavelength range of 200-800 nm with $1 \mathrm{~nm}$ measurement resolution. At least three repetitions per sample were conducted.

\section{Enzymatic Degradation of Cellulose Films}

Fast biodegradation of the tested films was measured in laboratory conditions by enzymatic hydrolysis. The measurements were carried out by using an enzyme mixture that contained four different commercial enzyme preparations: cellulase, mannase, xylanase and $\beta$-glucosidase. The activity of the prepared enzyme mixture was 31.6 FPU/ml (filter paper unit/ml) and it was prepared as described by Tenkanen et al. [31]. The film samples were cut into small pieces of ca. $80 \mathrm{~mm}^{2}$ and placed in $50 \mathrm{ml}$ falcon tubes. The moisture content of each specimen was determined since the needed enzyme mixture was added based on the dry weight of the sample according to Eq. (1). $50 \mathrm{FPU} / \mathrm{g}$ of dry sample is needed for the hydrolysis experiment.
Volume of enzyme mixture

$$
=\frac{50 \frac{\mathrm{FPU}}{\mathrm{g}} \times \text { dry weight of cellulose }(\mathrm{g})}{\text { Activity of the prepared enzyme mixture }\left(\frac{\mathrm{FPU}}{\mathrm{ml}}\right)}
$$

The solid content of cellulose was kept constant ( $25 \mathrm{~g} / \mathrm{l})$ in the enzymatic studies. $0.1 \mathrm{M}$ sodium acetate buffer, $\mathrm{pH} 5$ was added to the falcon tubes containing the films samples. The incubation was started with the addition of the enzyme mixture and the test tubes were placed in a $40{ }^{\circ} \mathrm{C}$ water bath with mixing. Two replicates of each sample were measured. As a reference, a sample with no cellulose was measured. The hydrolysis time was constant $48 \mathrm{~h}$. A two-day incubation time was chosen for this study as it was shown to be enough for the degradation of pure cellulose samples. After the hydrolysis, the samples were centrifuged (3200 rpm for $10 \mathrm{~min}$ ) and the supernatant was retained and the enzymes were inactivated by boiling the supernatant in a glass vial for $5 \mathrm{~min}$. The precipitated enzymes were separated by centrifugation (3200 rpm for $10 \mathrm{~min}$ ). The dinitrosalicylic acid (DNS) was prepared and the reducing sugar content was analyzed from the supernatants by the DNS method, as described earlier [32]. The degree of hydrolysis of the cellulose samples was calculated by Eq. (2) by comparing the reducing sugar content to the initial amount of cellulose.

Degree of hydrolysis $(\%)=\frac{\operatorname{glucose} \text { content }\left(\frac{\mathrm{g}}{\mathrm{l}}\right)}{\text { initial cellulose content }\left(\frac{\mathrm{g}}{\mathrm{l}}\right)}$

\section{Pilot-Scale Composting Test}

Degradation of cellulose-based films in composting conditions was evaluated using modified EN standard 14045 (Packaging. Evaluation of the disintegration of packaging materials in practical oriented tests under defined composting conditions). In this modified method samples were attached to the plastic frames $(5 \times 5 \mathrm{~cm})$ buried inside composter bins in steel frames, and degradation was evaluated by estimating visually the remaining surface of the 
disintegrated sample in the frames during composting. A schematic image of the test is presented in SI 4. Degradation D can be calculated by Eq. (3),

$D=\frac{A_{i}-A_{t}}{A_{i}} \times 100$,

where $A_{i}$ is the initial surface of the sample in the frame and $A_{t}$ is the remaining surface of the sample in the frame. Four replicates were used for the each sample. Samples were taken out of exposure to the compost every 2 weeks and the degree of degradation (disintegration) was calculated. The test was performed in a 2001 composter bin (Biolan Ltd, Finland) with continuous aeration. The composter bin was filled with a mixture of biowaste (fresh fruit and vegetable waste reduced to particle sizes of approximately $5 \mathrm{~cm})$ and bulking agent (1:1 vol.). The bulking agent was a mixture of peat, bark of pine and cutter wood chips. More biowaste + bulking agent mixture was added to the composter bins after 1 and 4 weeks to maintain the temperature in the required level. Temperature and carbon dioxide evolution were measured during composting, and aeration was adjusted to maintain optimal composting conditions. The biowaste mixture was turned manually with the help of a digging for to break down clumps once a week during the first 4 weeks and after that every second week until the end of the experiment. The dry weight, $\mathrm{pH}$, organic matter and

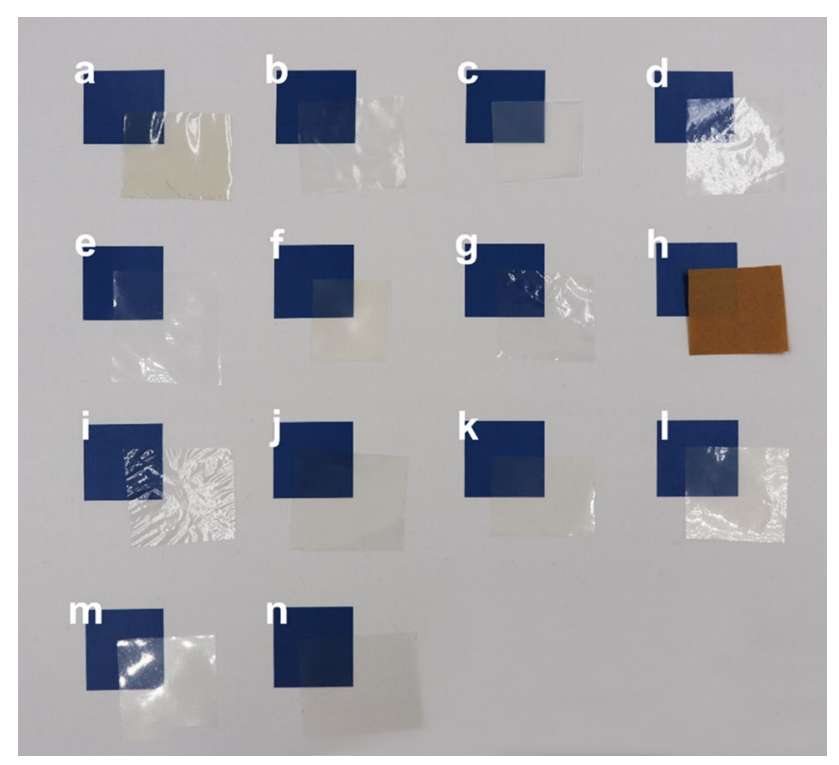

Fig. 1 Image of the fourteen cellulose-based films included in this study. (a) cellulose regenerated from IL, (b) CMC crosslinked by Alsalt, (c) nanocellulose, (d) methyl, cellulose (e) cellulose acetate, (f) paper partially dissolved by IL, (g) cellophane, (h) wet strength paper, (i) cellulose carbamate, (j) butylated hemicellulose DS 1, (k) butylated hemicellulose DS 0.4, (1) butylated hemicellulose DS 0.2, (m) cellulose palmitate $(\mathrm{C} 16),(\mathrm{n})$ cellulose octanoate $(\mathrm{C} 8)$ conductivity of the biowaste and produced compost were determined by EN 13040, EN 13037, EN 13039 and EN 13038. Carbon and nitrogen content of dried biowaste were analyzed by Flash 2000 EA CHNS-O (Thermo Fisher Scientific, USA) -analysator. The maturity of the compost after the test was measured by $\mathrm{CO}_{2}$ production test and nitrate- $\mathrm{N} /$ ammonium-N ratio as described by Vikman et al. [33]. When $\mathrm{CO}_{2}$ evolution is greater than $3 \mathrm{mg} \mathrm{CO}-\mathrm{C} / \mathrm{g} \mathrm{VS} / \mathrm{d}$ and the nitrate-N/ammonia-N ratio smaller than 1 , the compost is not considered stable and mature [34]. Volatile solids (VS) corresponds to the amount of organic matter in the compost.

\section{Results and Discussion}

\section{Film Preparation}

Seven of the fourteen cellulose-based films included in this study were self-made. The seven films were prepared either via solvent casting or via regeneration. The used preparation strategies are listed in Table 1. A selection of cellulosebased materials as diverse as possible was chosen for the study to compare the effect of different substituents and degrees of substitution on the film properties. Images of all films included in this study are presented in Fig. 1. Cellulose regenerated from IL, Carboxymethylcellulose (CMC) crosslinked by Al-salt, methyl cellulose, cellulose acetate, butylated hemicellulose DS: 1, butylated hemicellulose DS: 0.4 and butylated hemicellulose DS: 0.2 were prepared in this study and formed flexible and transparent films. Cellophane and wet strength paper were commercial film and paper. Nanocellulose, paper partially dissolved by IL, cellulose carbamate, cellulose palmitate, and cellulose octanoate were prepared at VTT and received for this study, which also formed flexible and transparent films. For all studied films a basic characterization: including optical, chemical, and mechanical, was prepared to verify the analysed materials.

\section{Optical Properties}

Ultraviolet-visible (UV-Vis) was used to measure the transparency of the cellulose-based films, since optical properties are important for film applications. In addition, cellulose samples are able to block UV light, since they absorb light in the UV range. As seen from Fig. 1, all cellulose films, except h) (wet strength paper) and c) (nanocellulose), look rather transparent. When the films were analysed by UV-Vis, a clear difference can be seen even between the transparent samples (a), (b), (d), (e), (f), (g), (i), (j), (k), (l), (m), (n). The UV-Vis profiles are presented in the SI 3. In the UV region (200-400 nm), the pure cellulose samples (e.g. cellophane) show lower transmittance than the chemically modified (e.g. cellulose acetate). This indicates that the substitution 


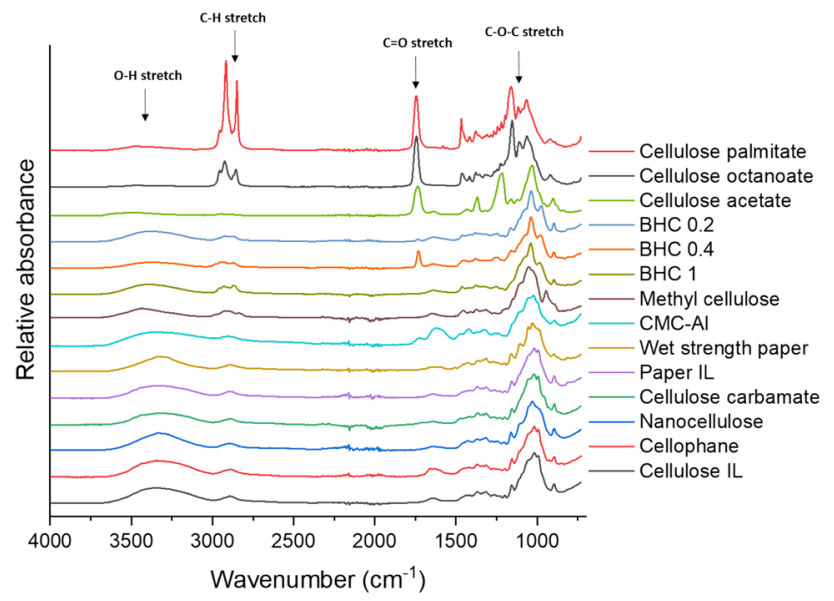

Fig. 2 ATR-FTIR spectra of all cellulose-based films and peak assignment

increases the transmittance of light in both UV- and visible light range. This trend is also seen for the butylated hemicellulose samples and has been previously reported for acetylated samples [35]. However, in the short wavelength end of the UV region, the butylated and acetylated samples absorbed UV to a greater extent than the rest of the samples. This behaviour has been previously reported for deacetylated cellulose acetate and pure cellulose acetate [36]. The only exception was cellulose regenerated from IL, which showed also absorption in the lower end of the UV region. This may be due to some traces of ionic liquid. It is reported that glucose exhibits a UV absorption band at $270 \mathrm{~nm}$ [37]. This is seen as a bend in the curve for the pure celluloses and modified celluloses with low DS. Wet strength paper is the only paper sample included in this study and shows no transmittance in the visible region. Nanocellulose film shows higher transmittance than paper but still clearly lower that the rest of the films. The small variability between pure cellulose samples may be due to the differences is sample thicknesses.

\section{ATR-FTIR Measurements}

The ATR-FTIR spectra of all 14 cellulose-based films were measured to determine the chemical structures and are presented in Fig. 2. The typical fingerprint area for cellulose is in the range of $800-1200 \mathrm{~cm}^{-1}$, which results from the stretching and vibrations in the cellulose backbone. This was seen for all cellulose-based films. The peak at $1150 \mathrm{~cm}^{-1}$ results from the $\mathrm{C}-\mathrm{O}-\mathrm{C}$ asymmetrical stretching, and the peaks around $1000 \mathrm{~cm}^{-1}$ results from $\mathrm{C}-\mathrm{C}, \mathrm{C}-\mathrm{OH}, \mathrm{C}-\mathrm{H}$ ring and side group vibrations [38]. The broad band in the $3600-3100 \mathrm{~cm}^{-1}$ region is due to the $-\mathrm{OH}$ stretching vibration of the hydroxyl groups on the cellulose backbone. In addition, bound water contributes to the intensity of this peak. The peak at $\sim 2800 \mathrm{~cm}^{-1}$ is due to the symmetrical $-\mathrm{CH}$ stretching. It can be observed, that the cellulose octanoate and cellulose palmitate samples have a much more intensive peak at this range, which is due to the long fatty acid substituents [39]. The strong peak at $1730 \mathrm{~cm}^{-1}$ for samples cellulose octanoate, cellulose palmitate, and cellulose acetate can be observed, which results from the stretching vibration of the carbonyl $(\mathrm{C}=\mathrm{O})$ bond in the esterase linkage within the substituents of these samples [40, 41]. The FT-IR spectrum for CMC crosslinked by Al-salt (CMC-Al) shows the presence of the carboxyl groups $(-\mathrm{COOH})$ at $1618 \mathrm{~cm}^{-1}$ [42]. The absorption peak of the carboxyl groups is shifted to higher wavenumbers due to the crosslinking with aluminum [43]. The absorbtion peak of carboxyl groups for pure CMC is at $1586 \mathrm{~cm}^{-1}$. Additionally, the intensity of the peak is lower for CMC-Al since the Al-crosslinking takes place with the $-\mathrm{COOH}$ groups. The comparison of $\mathrm{CMC}$ and CMC-Al spectra is presented in SI 1 Fig. 2. Butylated hemicellulose samples show changes at $2850-3100 \mathrm{~cm}^{-1}$, originating from $-\mathrm{CH}$ stretching, compared to the pure cellulose samples. These responses have been shown to originate from the methyl groups in the substituents that are introduced by etherification [44]. The peak seen at $1730 \mathrm{~cm}^{-1}$ for BHC DS: 0.4 results from carbonyl contamination during film preparation, since the freeze-dried sample did not show this peak.

\section{SEM Imaging}

The surface topography and microstructure of the samples were analyzed using field emission scanning electron microscopy (FE-SEM). The SEM images of all films are presented in SI 1. The films can be roughly categorized in three different groups: polymeric cellulose, nanofibrillar cellulose and cellulose fibers. All other films except nanocellulose and wet strength paper belong to the first category. For example cellulose dissolved in IL has been fully dissolved and a regenerated polymeric cellulose matrix is formed. Individual nanofibrils are visible in the SEM image of the nanocellulose film, displaying an interconnected nanofibrillar network. The nanocellulose fibrils are isolated from wood fibers by mechanical grinding breaking the wood fibers apart into nanofibrils [45]. Wet strength paper shows wood fibers, which are typically seen in regular paper. For the wet strength paper sample the fibers are already clearly seen with the $100 \times$ magnification, whereas for the polymeric cellulose sample, such as cellulose IL, only an even surface is seen with the $7500 \times$ magnification. The width of cellulose wood fiber is approximately $30 \mu \mathrm{m}$, whereas the width of a nanofiber is $5-30 \mathrm{~nm}$ and the cellulose molecules in the cellulose IL are impossible to detect with SEM. 


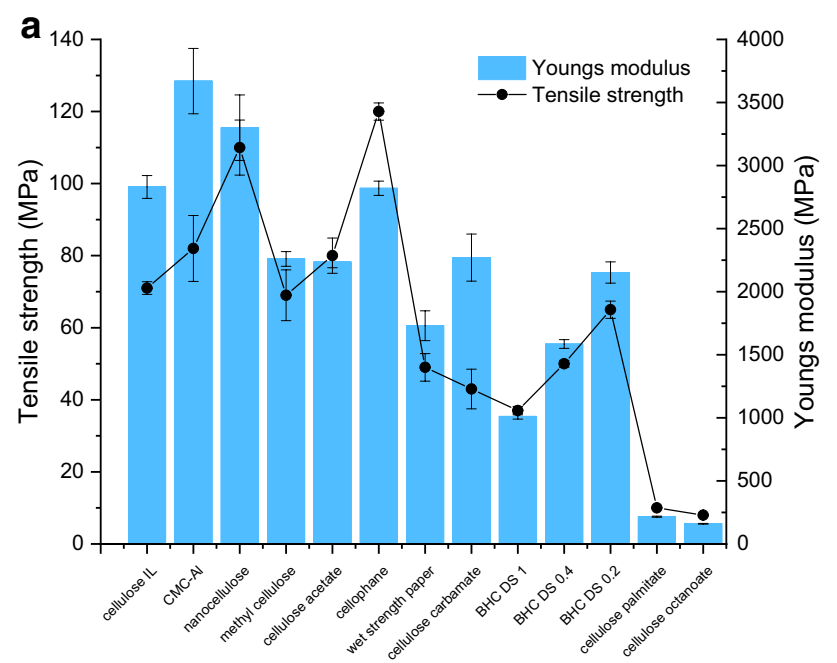

b

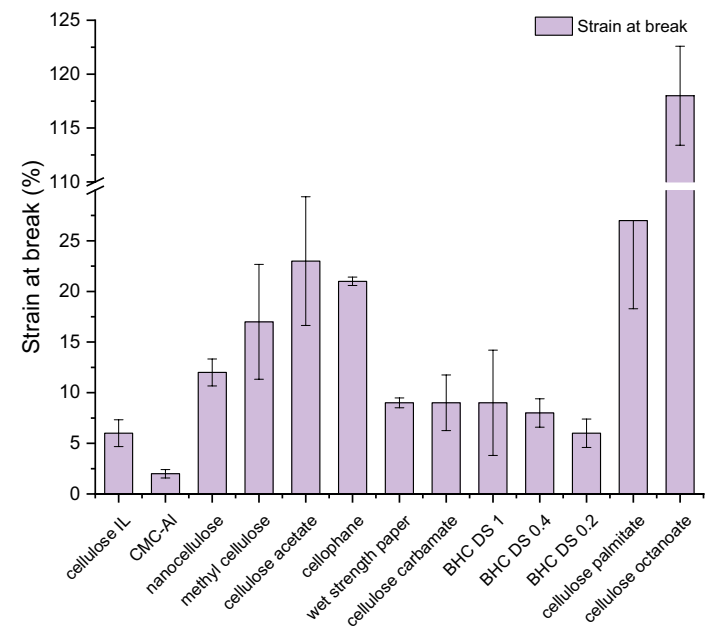

Fig. 3 Mechanical properties of cellulose-based films. a Tensile strength (MPa) and Young's modulus (MPa). b Percentage strain at break $(\%)$

\section{Mechanical Properties}

Mechanical properties including, Young's modulus (E), tensile strength, and percentage strain at break, for all cellulose-based films were measured. The results are presented in Fig. 3. Cellophane film has the highest tensile strength (120 MPa) with Young's modulus $2820 \mathrm{MPa}$, nanocellulose having the second highest values with tensile strength $110 \mathrm{MPa}$ and Young's modulus $3300 \mathrm{MPa}$. This result shows that nanocellulose film has mechanical properties comparable to the commercial cellophane film. The lowest tensile strength (8 MPa) and Young's Modulus (160 MPa) were measured for cellulose octanoate film. This film, however, showed clearly the highest percentage strain at break (118\%). Cellulose palmitate (DS: 1) and cellulose octanoate (DS: 1.2) films vary both in degree of substitution and in the length of the substituent. Effect of degree of substitution

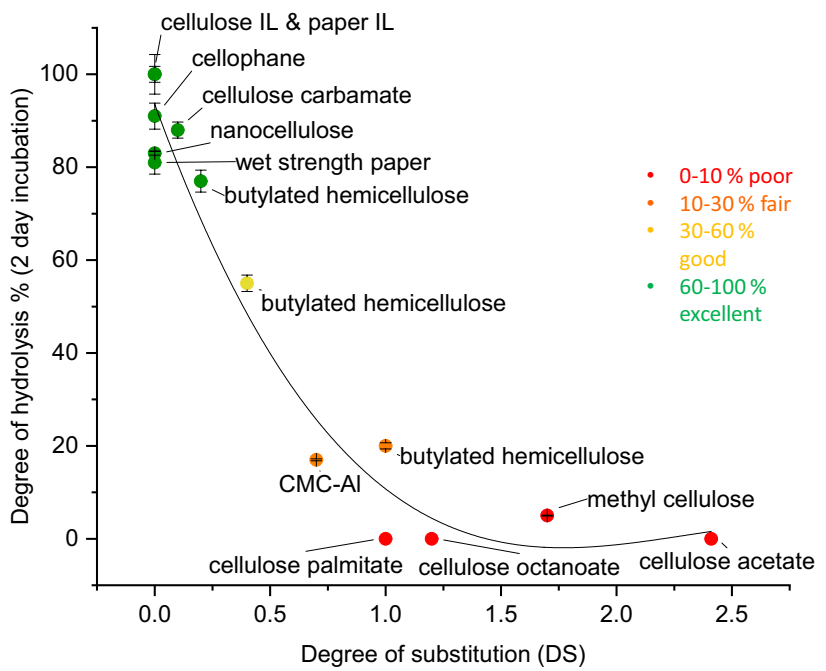

Fig. 4 Biodegradation of cellulose-based films by enzymatic hydrolysis in a 2-day incubation. The degree of hydrolysis (\%) is presented as the function of the degree of substitution (DS). Samples marked with green colour show excellent degradation, sample in yellow shows good degradation, samples in orange show fair degradation and samples in red show poor degradation (Color figure online)

and side-chain length on the mechanical properties of cellulose ester films has been studied previously [46]. Based on their findings, it can be observed that differences in DS values have a smaller effect on the mechanical properties than the side-chain length. Results in this study, correlate with this. In addition from the study by Joly et al. [47], it can be observed that with small DS values $(<2)$ the differences between DS values on the mechanical properties are minor. Additionally, it can be assumed, that as the cellulose palmitate with longer side chain length has higher tensile strength, the side-chains undergo crystallization enhancing the mechanical properties. For the butylated hemicellulose films it can be observed that the tensile strength and Young's modulus of the film decreased with an increase in the DS value. The increase in the number of substituents keeps the main chains from packing tightly in its crystalline structure leading to a lower tensile strength. On the contrary, the percentage strain at break increases with an increase DS values. This also results from the fact that the cellulose chains are not tightly packed and the substituents cause the polymer chains to slide past each other, causing a higher strain value. However, the effect of DS on the strain at break is not as significant as the effect on the tensile strength and Young's modulus. In addition, cellulose regenerated from IL has very good mechanical properties, better than cellulose acetate (CA). Almost all cellulose-based films exceed the tensile strength of commercial WEX paper and are in the same grade as commercial cellophane. 


\section{Enzymatic Degradation}

Enzymatic hydrolysis experiments were executed for all film samples and they are presented in Fig. 4. Results of the enzymatic biodegradation of all cellulose-based samples are presented as the function of the degree of substitution. The samples that have degraded the fastest are presented with green colour. These include mostly pure cellulose samples, without chemical modifications. The sample presented in yellow, butylated hemicellulose DS: 0.4 shows still good biodegradability. The film samples that are marked in orange show fair degradability, but the degree of biodegradation is already quite low $10-30 \%$. The film samples marked with red show poor or no biodegradation at all within the 2-day incubation period. Within the pure cellulose samples; cellophane, cellulose regenerated from IL, paper partially dissolved by IL, nanocellulose, WEX paper, small differences in the biodegradation rate can be observed. These result from the different crystalline forms of cellulose. Cellulose II is known to degrade faster than cellulose I and the results in this study correlate with this [29]. Regenerated celluloses, cellophane, cellulose IL and paper IL show the fastest hydrolysis rate exceeding the rate of cellulose I samples, WEX paper and nanocellulose. In addition, WEX paper has still remains of lignin, which also decreases the rate. Cellulose carbamate (DS 0.11) is also regenerated cellulose and has a faster hydrolysis rate compared to the cellulose I samples even though it is chemically modified. It can be assumed that the degree of substitution is still small enough to maintain the biodegradability of the cellulose film sample. The biodegradability of nanocellulose films has been studied previously and the results in this study are similar [33]. The butylated hemicellulose samples nicely show the exponential decrease in the biodegradation rate when an increase in the DS. The higher the degree of substitution the more the substituents are able to prevent the enzymes from attacking the cellulose backbone and degrade it. Samples containing an ester side group include cellulose palmitate, cellulose octanoate and cellulose acetate. It has been previously studied, that these samples require the addition of an esterase for biodegradation to occur [19]. In addition, the long fatty acid substituents likely hinder the binding of the cellulase enzymes on the cellulose backbone. CA film is highly substituted and the acetyl groups prevent the cellulases from attaching to each other. It is generally know that the presence of acyl groups hinders the degradation of naturally occurring acetylated polysaccharides (e.g. partially acetylated plant hemicelluloses) by enzymes [48]. Zero hydrolysis rate for cellulose acetate by enzymatic hydrolysis has also been reported in an earlier study [49]. The effect of the degree of substitution can be clearly

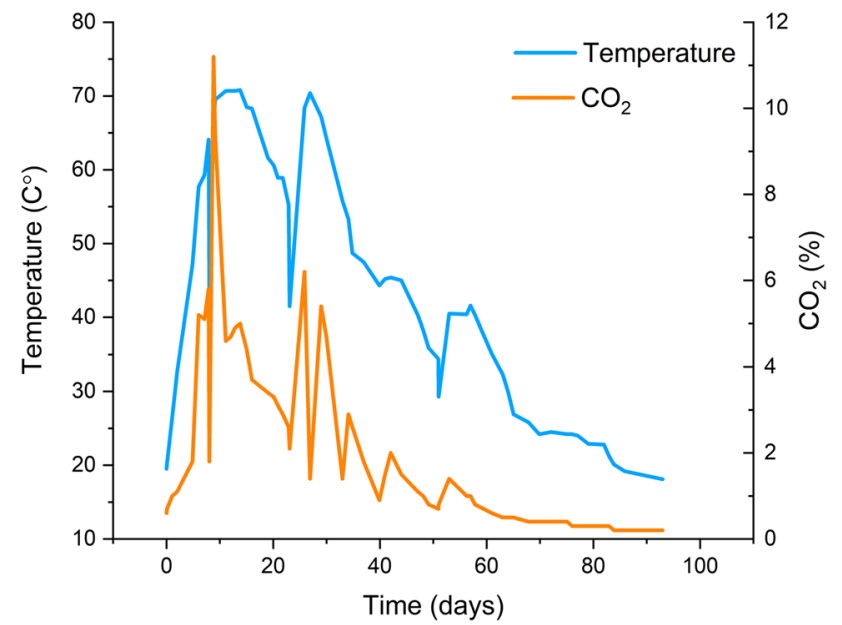

Fig. 5 Temperature and $\mathrm{CO}_{2}$ evolution during composting

observed from Fig. 4, as well as the minor effect of the type of substituent. It seems that the length or type of the substituent has a smaller effect on the biodegradation than the degree to which the glucose unit is substituted.

\section{Composting Test}

The pilot-scale composting test was done to evaluate the degradation of the cellulose-based films in a natural composting environment. The water content of the biowaste was $84 \%$ and organic matter content $95 \%(\mathrm{dw})$ in the beginning of composting. C/N-ratio of the biowaste and biowaste/ bulking agent mixture was 46 and 60 , respectively. While optimal $\mathrm{C} / \mathrm{N}$-ratio for composting has been reported to be between 25 and 40 it is highly dependent on the type of the composted raw material [50]. In the beginning of composting process organic acids are formed which enhance the growth of fungi and degradation of cellulose and lignin. As the process proceeded, the $\mathrm{pH}$ increased from 4.9 to 6.9 due the neutralization of organic acids and maturation of compost. Instead of the Rottegrad test, compost maturity was evaluated using carbon dioxide evolution test and $\mathrm{NO}_{3}-\mathrm{N} /$ $\mathrm{NH}_{4}-\mathrm{N}$ were measured to evaluate the compost maturity. After the 12 weeks of composting, carbon dioxide evolution was $3.1 \mathrm{mg} \mathrm{CO}-\mathrm{C} / \mathrm{g} \mathrm{VS} / \mathrm{d}$ and $\mathrm{NO}_{3}-\mathrm{N} / \mathrm{NH}_{4}-\mathrm{N}$ ratio was 6.9 . These values indicated that the compost was rather stable and correspond to the maturity level IV-V in Rottegrad-test [34]. The temperature and $\mathrm{CO}_{2}$ evolution during composting are presented in Fig. 5. The maximum temperature $70.7^{\circ} \mathrm{C}$ was reached already in the first 10 days of the experiment. According to the EN14045 standard, the test is valid if the temperature during the composting stays below $75^{\circ} \mathrm{C}$, the temperature is above $60^{\circ} \mathrm{C}$ for at least 1 week, and the temperature is above $40{ }^{\circ} \mathrm{C}$ for at least 4 consecutive weeks. The temperature decreased gradually close to the temperature of 
Fig. 6 Wet strength paper, methyl cellulose, cellulose acetate, nanocellulose and cellulose regenerated from IL attached in frames after 0,2 and 12 weeks of composting
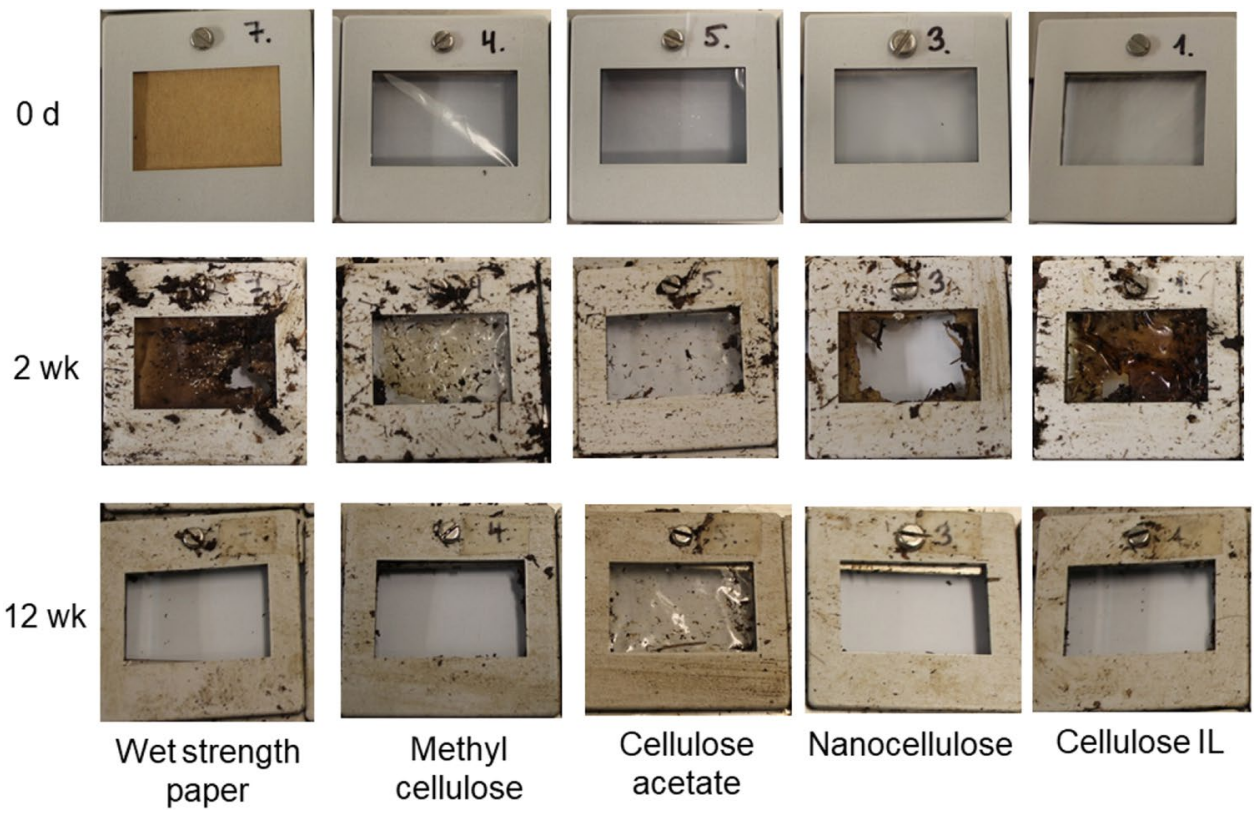

Methyl cellulose

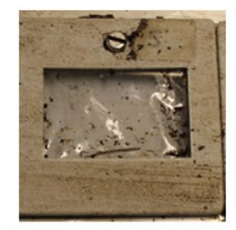

Cellulose acetate

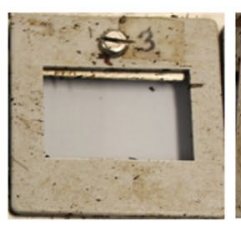

Nanocellulose

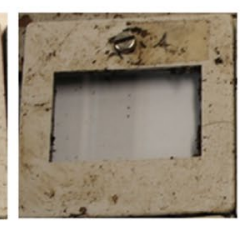

Cellulose IL surrounding air (ca. $+20^{\circ} \mathrm{C}$ ). The $\mathrm{CO}_{2}$ evolution increased to its maximum, $11 \%$ in 10 days, which indicates an increase in microbial activity during biowaste degradation. The mixing of the compost during the test can be seen as an increase of temperature and $\mathrm{CO}_{2}$ evolution as a result of activation of the biowaste degradation.

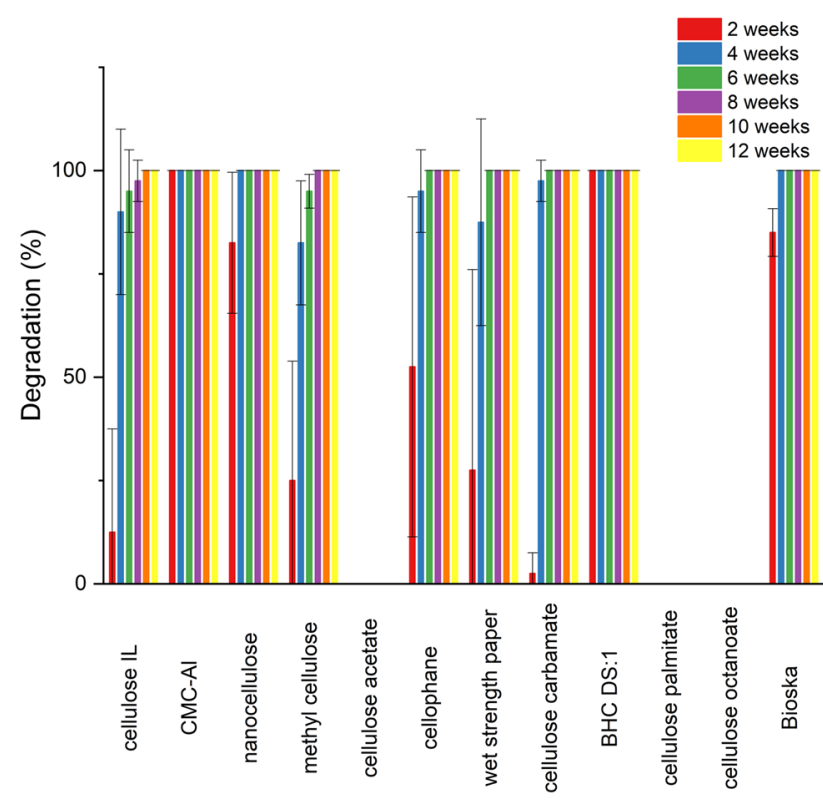

Fig. 7 Degradation of cellulose-based films in pilot-scale composting test. The degradation was evaluated visually every 2 weeks. Bioska (Plastiroll), commercial biodegradable biowaste bag, was used as a reference

\section{Degradation in Compost Conditions}

In the compost a natural ubiquitous microbial population present in the biowaste and bulking agent mixture starts the composting process and temperature increase happens spontaneously. Composting is a process that speeds up the natural decay of organic material by providing the ideal conditions for microbial population. Different communities of microorganisms predominate in various composting phases. The final end products of the composting are carbon dioxide, water, heat, and the relatively stable organic end product called humus. The degradation is initiated on the surface of the films as the enzymes attach to it. Degradation of the cellulose-based films during composting was evaluated visually according to the Eq. (3). Figure 6 shows the films attached to the frames and Fig. 7 the calculated degradation results.

CMC crosslinked by Al-salt and butylated hemicellulose (BHC DS: 1) degraded rapidly and after 2 weeks of composting the degradability of these films was $100 \%$. In the 2-day enzymatic hydrolysis studies these films showed fair biodegradation rate, $17 \%$ for $\mathrm{CMC}$ crosslinked by Al-salt and 20\% for BHC DS: 1 . For these samples, we can assume that the samples that degraded $10-30 \%$ in the enzymatic hydrolysis studies are able to fully disintegrate in composting conditions already after 2 weeks. Additionally, CMC and BHC are water-soluble, which may enhance the disintegration of the films in composting environment with high moisture content and in high temperature. All other films, except methyl cellulose, BHC and CMC, are not soluble in water and are not affected by dissolution in the composting studies. After 2 weeks of composting the regenerated cellulose films; cellulose IL, cellophane and cellulose carbamate 


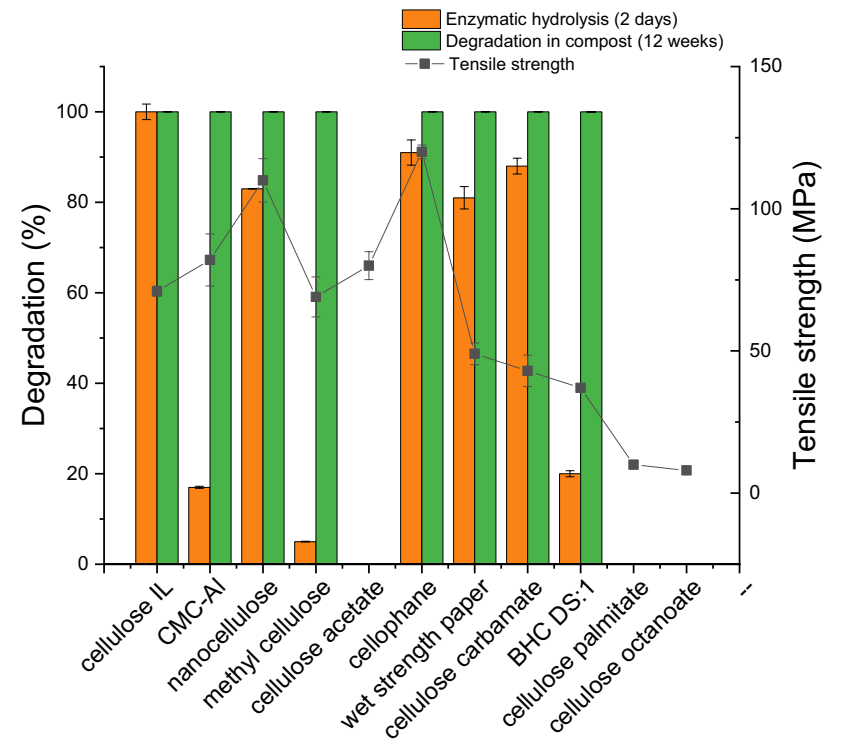

Fig. 8 Comparative figure of degradation in pilot-scale composting conditions, enzymatic hydrolysis and tensile strength of the cellulosebased films

showed surprisingly low degradation compared to the enzymatic hydrolysis after 2 days. However, all of these samples showed almost $100 \%$ degradability after 4 weeks of composting. Acetylated celluloses; cellulose acetate, cellulose palmitate and cellulose octanoate did not degrade in the composting experiment. These results are in line with the enzymatic biodegradation experiments, which gave similar results. Cellulose palmitate has the same DS as the BHC sample, which degraded completely in the compost. The fact that cellulose palmitate and octanoate samples did not degrade and BHC did, can be explained by the long fatty acid substituents on cellulose palmitate, which prevent the enzymes from attaching to the cellulose backbone. Methyl cellulose with DS 1.7 was fully degraded after 10 weeks of composting. The DS is still low enough for the enzymes to attach to the cellulose surface, but a longer time is already needed. In addition, it is not affected by dissolution as much as BHC and CMC since it dissolves best in cold water. In addition to material characteristics, the degradation rate of sample during composting is depended on the thickness of the film since the degradation is initiated at the surface. Therefore, degradation results obtained by visual evaluation should be utilized with certain reservations. The thicknesses of the films tested varied from 28 to $175 \mu \mathrm{m}$. However, no correlation related to the thickness was noted. Samples from all thickness grades showed degradation. In addition, the pilot-scale composting test correlates with the enzymatic studies, since in both of the test the samples with high DS: 2.5 and long substituents did not degrade.
Figure 8 presents a comparative figure of the degradation in pilot-scale composting, enzymatic hydrolysis and tensile strength. Nanocellulose and cellophane have the highest tensile strength, while still being readily degradable. A tightly packed structure does not prevent the enzymes from attacking the cellulose backbone. This trend can also be seen for the BHC samples, since BHC DS: 1 having the lowest tensile strength is least degraded in the enzymatic hydrolysis studies. A highly crystalline cellulose sample has a very tight structure with cellulose chains closely bound to each other leaving less space for enzymes to attach and initiate the hydrolysis process than in amorphous cellulose. However, it is known that even highly crystalline bacterial cellulose and Avicel are degraded by enzymatic hydrolysis [51-53]. A looser structure with cellulose chains wider apart would allow enzymes to attach more easily. However, if the cellulose chain is highly substituted the enzymes are not able to attach to the surface and move along the cellulose chain, since the substituent is blocking its way [54]. It can be concluded, that what most affects the biodegradability is the degree of substitution as well as the length of the substituent. These both hinder the binding of cellulose degrading enzymes on the surface and block the hydrolyzing process, which proceeds along the cellulose main chain.

\section{Conclusions}

In this study, we investigated the enzymatical biodegradability and pilot-scale composting of 14 cellulose-based film materials. Significantly, we have shown the diversity of cellulose-based films that can be fabricated from a renewable resource. We showed that chemical substituting decreases the enzymatic hydrolysis exponentially as the function of the degree of substitution, despite of what the substituent is. Additionally, increase in the length of the substituent hinders the biodegradability. Cellulose IL, CMC-Al, methyl cellulose, cellophane, wet strength paper, cellulose carbamate, and BHC DS: 1 disintegrated completely in the modified pilot-scale composting test EN 14045 indicating their suitability for composting.

Acknowledgements Open access funding provided by Technical Research Centre of Finland (VTT). This research was internally funded by VTT with a government grant and formed part of the Academy of Finland's Flagship Program under Project Nos. 318890 and 318891 (Competence Centre for Materials Bioeconomy, FinnCERES). The authors wish to thank Niina Torttila and Mirva Pyrhönen for skilful assistance in the laboratory, Christiane Laine, Pia Willberg-Keyriläinen, Tero Malm and Vesa Kunnari for providing film materials and Jaakko Pere for assistance with the enzymatic degradation studies.

Open Access This article is distributed under the terms of the Creative Commons Attribution 4.0 International License (http://creat ivecommons.org/licenses/by/4.0/), which permits unrestricted use, 
distribution, and reproduction in any medium, provided you give appropriate credit to the original author(s) and the source, provide a link to the Creative Commons license, and indicate if changes were made.

\section{References}

1. Plastics Europe (2018) Plastics - the Facts 2018. An analysis of European plastics production, demand and waste data. Association for Plastics Manufacturers, European Association of Plastics Recycling, Brussels

2. Anthony Browne M, Crump P, Niven SJ et al (2011) Accumulation of microplastic on shorelines woldwide: sources and sinks. Environ Sci Technol 45:9175-9179. https://doi.org/10.1021/es201 $811 \mathrm{~s}$

3. Jambeck JR, Geyer R, Wilcox C et al (2015) Plastic waste inputs from land into the ocean. Science 347:768-771. https://doi. org/10.1126/science. 1260352

4. Klemm, D., Philipp, B., Heinze, T., Heinze, U. and Wagenknecht W (1998) Comprehensive cellulose chemistry, vol 1: fundamentals and analytical methods. Wiley-VCH Verlag GmbH, Weinheim

5. Klemm D, Heublein B, Fink H-P, Bohn A (2005) Cellulose: fascinating biopolymer and sustainable raw material. Angew Chem Int Ed 44:3358-3393. https://doi.org/10.1002/anie.200460587

6. Holik H (2013) Handbook of paper and board. Wiley-VCH Verlag $\mathrm{GmbH} \& \mathrm{Co} . \mathrm{KGaA}$, Weinheim

7. Wang S, Lu A, Zhang L (2016) Recent advances in regenerated cellulose materials. Prog Polym Sci 53:169-206. https://doi. org/10.1016/J.PROGPOLYMSCI.2015.07.003

8. Johansson C, Bras J, Mondragon I et al (2012) Renewable fibers and bio-based materials for packaging applications-a review of recent developments. BioResources 7:2506-2552. https://doi. org/10.15376/biores.7.2.2506-2552

9. Wypych G (2013) Handbook of material weathering. Handbook of material weathering, 6th edn. ChemTec Publishing, Toronto, pp 829-849

10. Klyosov AA (1990) Trends in biochemistry and enzymology of cellulose degradation. Biochemistry 29:10577-10585. https://doi. org/10.1021/bi00499a001

11. Pérez J, Muñoz-Dorado J, de la Rubia T, Martínez J (2002) Biodegradation and biological treatments of cellulose, hemicellulose and lignin: an overview. Int Microbiol 5:53-63. https://doi. org/10.1007/s10123-002-0062-3

12. Lindman B, Karlström G, Stigsson L (2010) On the mechanism of dissolution of cellulose. J Mol Liq 156:76-81. https://doi. org/10.1016/J.MOLLIQ.2010.04.016

13. Simon J, Müller HP, Koch R, Müller V (1998) Thermoplastic and biodegradable polymers of cellulose. Polym Degrad Stab 59:107-115. https://doi.org/10.1016/S0141-3910(97)00151-1

14. Buchanan CM, Gardner RM, Komarek RJ (1993) Aerobic biodegradation of cellulose acetate. J Appl Polym Sci 47:1709-1719. https://doi.org/10.1002/app.1993.070471001

15. Komarek RJ, Gardner RM, Buchanan CM, Gedon S (1993) Biodegradation of radiolabeled cellulose acetate and cellulose propionate. J Appl Polym Sci 50:1739-1746. https://doi.org/10.1002/ app.1993.070501009

16. Gardner RM, Buchanan CM, Komarek R et al (1994) Compostability of cellulose acetate films. J Appl Polym Sci 52:1477-1488. https://doi.org/10.1002/app.1994.070521012

17. Cantor PA, Mechalas BJ (1969) Biological degradation of cellulose acetate reverse-osmosis membranes. J Polym Sci Part C Polym Symp 28:225-241. https://doi.org/10.1002/polc.50702 80119
18. Puls J, Wilson SA, Hölter D (2011) Degradation of cellulose acetate-based materials: a review. J Polym Environ 19:152-165. https://doi.org/10.1007/s10924-010-0258-0

19. Ho LC, Martin DD, Lindemann WC (1983) Inability of microorganisms to degrade cellulose acetate reverse-osmosis membranes. Appl Environ Microbiol 45:418-427

20. Haske-Cornelius O, Pellis A, Tegl G et al (2017) Enzymatic systems for cellulose acetate degradation. Catalysts 7:1-15. https:// doi.org/10.3390/catal7100287

21. Rimdusit S, Jingjid S, Damrongsakkul S et al (2008) Biodegradability and property characterizations of methyl cellulose: effect of nanocompositing and chemical crosslinking. Carbohydr Polym 72:444-455. https://doi.org/10.1016/J.CARBPOL.2007.09.007

22. Betty Anita B, Thatheyus AJ, Vidhya R (2013) Biodegradation of carboxymethyl cellulose employing Cheatomium globosum MTCC 2193. Sci Int 1:92-97

23. Van Ginkel CG, Gayton S (1996) The biodegradability and nontoxicity of carboxymethyl cellulose (DS 0.7) and intermediates. Environ Toxicol Chem 15:270-274. https://doi.org/10.1897/15515028(1996)015\%3c0270:TBANOC\%3e2.3.CO;2

24. Swift G (2000) Polymers, environmentally degradable. In: KirkOthmer encyclopedia of chemical technology. Wiley, Hoboken

25. van der Zee M (2005) In: Bastioli C (ed) Handbook of biodegradable polymers. Rapra Technology Limited, Shawbury, pp 1-22

26. European Standards (2003) EN14046, Packaging-evaluation of the ultimate aerobic biodegradability of packaging materials under controlled composting conditions-Method by analysis of released carbon dioxide. German version EN. 14046:2003

27. Battista OA (1950) Hydrolysis and crystallization of cellulose. Ind Eng Chem 42:502-507

28. O'Sullivan AC (1997) Cellulose: the structure slowly unravels. Cellulose 4:173-207. https://doi.org/10.1023/A:1018431705579

29. Wada M, Ike M, Tokuyasu K (2010) Enzymatic hydrolysis of cellulose I is greatly accelerated via its conversion to the cellulose II hydrate form. Polym Degrad Stab 95:543-548. https://doi. org/10.1016/J.POLYMDEGRADSTAB.2009.12.014

30. Chundawat SPS, Bellesia G, Uppugundla N et al (2011) Restructuring the crystalline cellulose hydrogen bond network enhances its depolymerization rate. J Am Chem Soc 133:11163-11174. https://doi.org/10.1021/ja2011115

31. Tenkanen M, Hausalo T, Siika-Aho M et al (1995) Use of enzymes in combination with anion exchange chromatography in the analysis of carbohydrate composition of Kraft pulp. In: 8th International symposium on wood and pulping chemistry, Helsinki

32. Sumner JB (1924) The estimation of sugar in diabetic urine, using dinitrosalicylic acid. J Biol Chem 62:287-290

33. Vikman M, Vartiainen J, Tsitko I, Korhonen P (2015) Biodegradability and compostability of nanofibrillar cellulose-based products. J Polym Environ 23:206-215. https://doi.org/10.1007/s1092 4-014-0694-3

34. Itävaara M, Vikman M, Liisa M, Vuorinen A (2010) Maturity tests for composts-verification of a test scheme for assessing maturity. Compos Sci Util 18:174-183. https://doi.org/10.1080/10656 57X.2010.10736953

35. Ogawa K, Hirai I, Shimasaki C et al (1999) Simple determination method of degree of substitution for starch acetate. Bull Chem Soc Jpn 72:2785-2790. https://doi.org/10.1246/bcsj.72.2785

36. Rowen JW, Hunt CM, Plyler EK (1947) Absorption spectra in the detection of chemical changes in cellulose and cellulose derivatives. J Res Natl Bur Stand (1934) 39:133-140

37. Kaijanen L, Paakkunainen M, Pietarinen S et al (2015) Ultraviolet detection of monosaccharides: multiple wavelength strategy to evaluate results after capillary zone electrophoretic separation. Int J Electrochem Sci 10:2950-2961 
38. Fan M, Dai D, Huang B (2012) Fourier transform infrared spectroscopy for natural fibres. In: Salih S (ed) Fourier transformmaterials Analysis. InTech, Rijeka, pp 45-69

39. Freire CSR, Silvestre AJD, Neto CP, Rocha RMA (2005) An efficient method for determination of the degree of substitution of cellulose esters of long chain aliphatic acids. Cellulose. https:// doi.org/10.1007/s10570-005-2203-2

40. Willberg-Keyriläinen P, Talja R, Asikainen S et al (2016) The effect of cellulose molar mass on the properties of palmitate esters. Carbohydr Polym 151:988-995. https://doi.org/10.1016/J. CARBPOL.2016.06.048

41. Frisoni Giovanna, Massimo Baiardo A, Scandola M et al (2001) Natural Cellulose fibers: heterogeneous acetylation kinetics and biodegradation behavior. Biomacromol 2:476-482. https://doi. org/10.1021/BM0056409

42. Pushpamalar V, Langford SJ, Ahmad M, Lim YY (2006) Optimization of reaction conditions for preparing carboxymethyl cellulose from sago waste. Carbohydr Polym 64:312-318. https:// doi.org/10.1016/j.carbpol.2005.12.003

43. Liu J, Zhang C, Miao D et al (2018) Preparation and characterization of carboxymethylcellulose hydrogel fibers. J Eng Fibers Fabrics 13(6):6-13

44. Nypelö T, Laine C, Aoki M et al (2016) Etherification of woodbased hemicelluloses for interfacial activity. Biomacromol 17:1894-1901. https://doi.org/10.1021/acs.biomac.6b00355

45. Vartiainen J, Pöhler T, Sirola K et al (2011) Health and environmental safety aspects of friction grinding and spray drying of microfibrillated cellulose. Cellulose 18:775-786. https://doi. org/10.1007/s10570-011-9501-7

46. Crépy L, Chaveriat L, Banoub J et al (2009) Synthesis of cellulose fatty esters as plastics-influence of the degree of substitution and the fatty chain length on mechanical properties. Chemsuschem 2:165-170. https://doi.org/10.1002/cssc.200800171

47. Joly N, Martin P, Liénard L et al (2006) Effect of degree of substitution on the mechanical and thermomechanical properties of lauroyl cellulose ester films. e-Polymers 6:1-9. https://doi. org/10.1515/epoly.2006.6.1.895

48. Biely P (2012) Microbial carbohydrate esterases deacetylating plant polysaccharides. Biotechnol Adv 30:1575-1588. https:// doi.org/10.1016/j.biotechadv.2012.04.010

49. Itävaara M, Siika-aho M, Viikari L (1999) Enzymatic degradation of cellulose-based materials. J Polym Environ 7:67-73. https:// doi.org/10.1023/A:1021804216508

50. Tuomela M, Vikman M, Hatakka A, Itävaara M (2000) Biodegradation of lignin in a compost environment: a review. Bioresour Technol 72:169-183. https://doi.org/10.1016/S0960 -8524(99)00104-2

51. Yang B, Dai Z, Ding SY, Wyman CE (2011) Enzymatic hydrolysis of cellulosic biomass. Biofuels 2:421-450. https://doi. org/10.4155/bfs. 11.116

52. Rovera C, Ghaani M, Santo N et al (2018) Enzymatic hydrolysis in the green production of bacterial cellulose nanocrystals. ACS Sustain Chem Eng 6:7725-7734. https://doi.org/10.1021/acssu schemeng. 8 b00600

53. Ling Z, Chen S, Zhang X et al (2017) Unraveling variations of crystalline cellulose induced by ionic liquid and their effects on enzymatic hydrolysis. Sci Rep 7:10230. https://doi.org/10.1038/ s41598-017-09885-9

54. Estela R, Luis J (2013) Hydrolysis of biomass mediated by cellulases for the production of sugars. In: Sustainable degradation of lignocellulosic biomass-techniques, applications and commercialization. InTech, Rijeka

55. Tammelin T, Hippi U, Salminen A (2013) WO 2013/060934 A2

56. Tanaka A, Khakalo A, Hauru L et al (2018) Conversion of paper to film by ionic liquids: manufacturing process and properties. Cellulose 25:6107-6119. https://doi.org/10.1007/s10570-018-1944-7

57. Ropponen J, Talja R, Willberg-Keyriläinen P et al (2016) WO 2016/193542 A1

Publisher's Note Springer Nature remains neutral with regard to jurisdictional claims in published maps and institutional affiliations. 